\title{
Fixed point theorems of ordered contractive mappings on cone metric spaces over Banach algebras
}

\author{
Jiandong Yin*, Tao Wang and Qi Yan
}

"Correspondence: yjdaxf@163.com Department of Mathematics, Nanchang University, Nanchang, 330031, China

\begin{abstract}
In this paper, the concept of ordered contractive mappings is introduced on cone metric spaces over Banach algebras, and some existence theorems of fixed points for such mappings are obtained. As an application of a result, an example is given at the end of the paper.

MSC: $54 \mathrm{H} 25 ; 47 \mathrm{H} 10$

Keywords: fixed point theorems; ordered contractive mappings; cone metric spaces over Banach algebras; spectral radius
\end{abstract}

\section{Introduction}

The study of fixed points for nonlinear mappings is an important subject of nonlinear function analysis, and the theory of fixed points is frequently applied to nonlinear integral equations and differential equations (see [1-5] and the references given there). Besides, the work of Caristi [6], in which a partial ordering was introduced in metric spaces by a function and a fixed point theorem was proved, is worthy of attention. In 2007, in the work of Huang and Zhang [7], the concept of cone metric spaces as a generalization of general metric spaces was introduced, in which the distance $d(x, y)$ of $x$ and $y$ is defined to be a vector in an ordered Banach space $E$. It was also proved that the Banach contraction principle remains true in the setting of cone metric spaces. After that, based on the work of Huang and Zhang [7], the fixed point results of some mappings with certain contractive property on cone metric spaces appeared like mushrooms after rain (see [8-14] and the references therein and [15-23]). Among those works, the results of [13,14] attract much attention since they give an answer to the natural problem that whether cone metric spaces are equivalent to metric spaces in terms of the existence of fixed points of the involved mappings. Concretely, the authors showed that any cone metric space $(X, d)$ is equivalent to a usual metric space $\left(X, d^{*}\right)$ if the real-valued metric function $d^{*}$ is defined by a nonlinear scalarization function $\xi_{e}$ (see [13]) or by a Minkowski functional $q_{e}$ (see [14]).

In 2013, in order to generalize the Banach contraction principle to a more general form, Liu and Xu $[24,25]$ introduced the concept of cone metric spaces over Banach algebras by replacing Banach spaces with Banach algebras and proved some fixed point theorems of generalized Lipschitz mappings with weaker and natural conditions on the generalized 
Lipschitz constant $k$ by means of spectral radius and pointed out that it is significant to introduce the concept of cone metric spaces over Banach algebras because it can be proved that cone metric spaces over Banach algebras are not equivalent to metric spaces in terms of the existence of fixed points of the generalized Lipschitz mappings (see [25]). Liu and $\mathrm{Xu}$ [25] showed that their results could not be reduced to a consequence of corresponding results in metric spaces by means of the methods in the literature. In 2014, Xu and Radenović [26] keenly discovered that the proofs of the main results of [25] strongly depend on the condition that the underlying solid cone is normal. Naturally, they considered that whether the conclusions of [25] remain valid if 'normal' is deleted from the hypotheses. By means of some properties of spectral radius, they proved that the main results of [25] still hold without the assumption of normality of the cone involved. Hence $\mathrm{Xu}$ and Radenović [26] improved the results of [25].

In this paper, on the basis of $[25,26]$, we introduce a partial ordering given by a continuous function in cone metric spaces over Banach algebras as well as the concept of ordered contractive mappings that differ from the known contractive mappings, and present several fixed point results of such mappings under some natural conditions. Finally, as an application of one of our results, we give a concrete example.

\section{Preliminaries}

Consistent with Huang and Zhang [7] and Liu and $\mathrm{Xu}$ [25], the following definitions and results are needed in the sequel.

Let $\mathcal{A}$ always be a real Banach algebra, that is, $\mathcal{A}$ is a real Banach space in which an operation of multiplication is defined, subject to the following properties (for all $x, y, z \in \mathcal{A}$, $\alpha \in \mathbb{R}):$

(1) $(x y) z=x(y z)$;

(2) $x(y+z)=x y+x z$ and $(x+y) z=x z+y z$;

(3) $\alpha(x y)=(\alpha x) y=x(\alpha y)$;

(4) $\|x y\| \leq\|x\|\|y\|$.

Here and subsequently, we assume that a Banach algebra has a unit (i.e., a multiplicative identity) $e$ such that $e x=x e=x$ for all $x \in \mathcal{A}$. $x \in \mathcal{A}$ is said to be invertible if there is an inverse element $y \in \mathcal{A}$ such that $x y=y x=e$. The inverse of $x$ is denoted by $x^{-1}$. We refer the reader to [25] for more details.

A non-empty closed convex subset $P$ of a Banach algebra $\mathcal{A}$ is called a cone if

(i) $\{\theta, e\} \subset P$;

(ii) $\alpha P+\beta P \subset P$;

(iii) $P^{2}=P P \subset P$;

(iv) $P \cap(-P)=\{\theta\}$,

where $\theta$ denotes the null of the Banach algebra $\mathcal{A}$.

Fix a cone $P \subset \mathcal{A}$, a partial ordering ' $\preceq$ ' with respect to $P$ can be defined by $x \preceq y$ if and only if $y-x \in P$. $x \prec y$ stands for $x \preceq y$ and $x \neq y$. $x \ll y$ stands for $y-x \in \operatorname{int}(P)$, here int $(P)$ denotes the interior of $P$. $P$ is called a solid cone if $\operatorname{int}(P) \neq \emptyset$. $P$ is called normal if there exists a positive constant $N$ such that for all $x, y \in \mathcal{A}, \theta \preceq x \preceq y \Rightarrow\|x\| \leq N\|y\|$.

Definition 2.1 ([25]) Let $X$ be a non-empty set and $\mathcal{A}$ be a real Banach algebra. Suppose that the mapping $d: X \times X \rightarrow \mathcal{A}$ satisfies:

(1) $\theta \preceq d(x, y)$ for all $x, y \in X$ and $d(x, y)=\theta$ if and only if $x=y$; 
(2) $d(x, y)=d(y, x)$ for all $x, y \in X$;

(3) $d(x, y) \preceq d(x, z)+d(z, y)$ for all $x, y, z \in X$.

Then $d$ is called a cone metric on $X$ and $(X, d)$ is called a cone metric space over the Banach algebra $\mathcal{A}$.

See [25] for some examples of cone metric spaces over Banach algebras.

Definition $2.2([25])$ Let $(X, d)$ be a cone metric space over the Banach algebra $\mathcal{A}, x \in X$ and let $\left\{x_{n}\right\}$ be a sequence in $X$. Then:

(1) $\left\{x_{n}\right\}$ converges to $x$ if for each $c \in \mathcal{A}$ with $\theta \ll c$, there is a natural number $N$ such that $d\left(x_{n}, x\right) \ll c$ for all $n>N$. We denote this by $\lim _{n \rightarrow \infty} x_{n}=x$ or $x_{n} \rightarrow x$.

(2) $\left\{x_{n}\right\}$ is a Cauchy sequence if for each $c \in \mathcal{A}$ with $\theta \ll c$, there is a natural number $N$ such that $d\left(x_{n}, x_{m}\right) \ll c$ for all $n, m>N$.

(3) $(X, d)$ is a complete cone metric space if every Cauchy sequence is convergent.

Definition 2.3 Let $(X, d)$ be a cone metric space over the Banach algebra $\mathcal{A}$ and $\varphi: X \rightarrow \mathcal{A}$ be a mapping. A relation ' $\leq$ ' (for the sake of differing from the partial ordering ' $\preceq$ ' in $\mathcal{A}$, we denote it by ' $\leq$ ') in $X$ is defined as follows:

$$
x, y \in X, \quad x \leq y \quad \text { if and only if } \quad d(x, y) \preceq \varphi(x)-\varphi(y) .
$$

Clearly ' $\leq$ ' is a partial ordering in $X$ and $x \leq y$ implies $\varphi(x) \succeq \varphi(y)$. Here we call it the partial ordering induced by $\varphi$. Meanwhile, $(X, d)$ is called a partial ordering cone metric space over the Banach algebra $\mathcal{A}$.

Definition 2.4 Let $(X, d)$ be a partial ordering cone metric space over the Banach algebra $\mathcal{A}$. We say that $x, y \in X$ are comparable if $x \leq y$ or $y \leq x$ holds.

If $x \leq y$ and $x \neq y$, we write $x<y$. We write $x=x \vee y$ if $y \leq x$ and write $y=x \vee y$ if $x \leq y$. The same notions as those in Definition 2.4 can be defined in $\mathcal{A}$ as follows: For any $x, y \in \mathcal{A}$, if $x \preceq y$ or $y \preceq x$ holds, we say that $x$ and $y$ are comparable. Let $u, v \in \mathcal{A}$. Similarly, we write $v=u \vee v$ if $u \preceq v$ and write $u=v \vee u$ if $v \preceq u$. From Definition 2.3, it is evident that $\varphi(x)$ and $\varphi(y)$ are comparable in $\mathcal{A}$ if $x, y \in X$ are comparable.

Remark 2.1 Suppose that $\mathcal{A}$ is a real Banach algebra, $u, v, w \in \mathcal{A}$. The following results are clear.

(i) If $u$ and $v$ are comparable, then $u-v$ and $v-u$ are comparable and $\theta \preceq(u-v) \vee(v-u)$.

(ii) If $u$ and $v, u$ and $w$ together with $v$ and $w$ are comparable, then

$$
(u-v) \vee(v-u) \preceq((u-w) \vee(w-u))+((w-v) \vee(v-w))
$$

Definition 2.5 Let $(X, d)$ be a cone metric space over the Banach algebra $\mathcal{A}$ and $A: X \rightarrow X$ be a mapping. We say that $A$ is continuous if for any $\left\{x_{n}\right\} \subset X, x_{n} \rightarrow x$ implies $A x_{n} \rightarrow A x$ $(n \rightarrow \infty)$.

In the rest of this section, we always assume that $\mathcal{A}$ is a real Banach algebra and $(X, d)$ is a complete partial ordering cone metric space over $\mathcal{A}$ with the partial ordering ' $\leq$ ' induced 
by $\varphi$, where $\varphi: X \rightarrow \mathcal{A}$ is continuous, $P$ is a solid cone of $\mathcal{A}$ which gives the partial ordering ' ' in $\mathcal{A}$.

Definition 2.6 A mapping $A: X \rightarrow X$ is said to be $\varphi$-ordered contractive if there exists $k \in P$ with $0 \leq r(k)<1$ such that for any $x, y \in X$, if $x$ and $y$ are comparable, then $A x$ and $A y$ are comparable and

$$
(\varphi(A x)-\varphi(A y)) \vee(\varphi(A y)-\varphi(A x)) \preceq k[(\varphi(x)-\varphi(y)) \vee(\varphi(y)-\varphi(x))] .
$$

Remark 2.2 See Example 3.1 for a support example of Definition 2.3, Definition 2.4, Definition 2.5 and Definition 2.6.

Lemma 2.1 ([7]) Let $\left\{x_{n}\right\}$ and $\left\{y_{n}\right\}$ be two sequences in $X$ and $x_{n} \rightarrow x_{0}, y_{n} \rightarrow y_{0}$ as $n \rightarrow \infty$. Then $d\left(x_{n}, y_{n}\right) \rightarrow d\left(x_{0}, y_{0}\right)(n \rightarrow \infty)$.

Lemma 2.2 Let $u, v_{n} \in X(n=1,2, \ldots)$. If for any natural number $n, u$ and $v_{n}$ are comparable and $v_{n} \rightarrow v_{0}(n \rightarrow \infty)$, then $u$ and $v_{0}$ are comparable.

Proof Since for any natural number $n, u$ and $v_{n}$ are comparable, there exists a subsequence $\left\{v_{n_{k}}\right\}$ of $\left\{v_{n}\right\}$ such that for any $k, u \leq v_{n_{k}}$ or $v_{n_{k}} \leq u$. Without loss of generality, we assume that for any $k, u \leq v_{n_{k}}$. As $v_{n} \rightarrow v_{0}$ when $n \rightarrow \infty$, we have $v_{n_{k}} \rightarrow v_{0}$ as $k \rightarrow \infty$. By Lemma 2.1 and the continuity of $\varphi$ and noting $u \leq v_{n_{k}}$ for all $k \geq 1$, we have

$$
d\left(u, v_{0}\right)=\lim _{k \rightarrow \infty} d\left(u, v_{n_{k}}\right) \preceq \lim _{k \rightarrow \infty}\left(\varphi(u)-\varphi\left(v_{n_{k}}\right)\right)=\varphi(u)-\varphi\left(v_{0}\right) .
$$

So $u \leq v_{0}$. That is $u$ and $v_{0}$ are comparable.

Lemma 2.3 Let $u_{n}, v_{n} \in X(n=0,1,2, \ldots)$. Iffor any natural number $n, u_{n}$ and $v_{n}$ are comparable and $u_{n} \rightarrow u_{0}, v_{n} \rightarrow v_{0}(n \rightarrow \infty)$, then $u_{0}$ and $v_{0}$ are comparable. In particular, if for any natural number $n, u_{n} \leq v_{n}$ and $u_{n} \rightarrow u_{0}, v_{n} \rightarrow v_{0}(n \rightarrow \infty)$, then $u_{0} \leq v_{0}$.

Proof Because the proof is similar to that of Lemma 2.2, we omit it.

Lemma 2.4 ([26]) Let $x, y$ be vectors in $\mathcal{A}$. If $x$ and $y$ commute, then the spectral radius $r$ satisfies the following properties:

(i) $r(x y) \leq r(x) r(y)$;

(ii) $r(x+y) \leq r(x)+r(y)$;

(iii) $|r(x)-r(y)| \leq r(x-y)$.

Lemma 2.5 ([26]) Let $k \in \mathcal{A}$. If $0 \leq r(k)<1$, then $e-k$ is invertible and $r\left((e-k)^{-1}\right) \leq$ $(1-r(k))^{-1}$.

\section{Main results}

In this section, we will present the main results and their proofs. For simplicity, we always assume that $\mathcal{A}$ is a real Banach algebra and $(X, d)$ is a complete partial ordering cone metric space over $\mathcal{A}$ with the partial ordering ' $\leq$ ' induced by $\varphi$, where $\varphi: X \rightarrow \mathcal{A}$ is continuous. Let $P$ be a normal solid cone of $\mathcal{A}$ which gives the partial ordering ' $\leq$ ' in $\mathcal{A}$. 
Theorem 3.1 If a continuous mapping $A: X \rightarrow X$ is $\varphi$-ordered contractive and there exists $x_{0} \in X$ such that $x_{0}$ and $A x_{0}$ are comparable, then $A$ has a fixed point $x^{*}$ in $X$, that is, $A x^{*}=x^{*}$. Furthermore, the iterative sequence $x_{n}=A x_{n-1}(n=1,2, \ldots)$ converges to $x^{*}$ and

$$
d\left(x^{*}, x_{0}\right) \preceq(e-k)^{-1}\left[\left(\varphi\left(A x_{0}\right)-\varphi\left(x_{0}\right)\right) \vee\left(\varphi\left(x_{0}\right)-\varphi\left(A x_{0}\right)\right)\right],
$$

where $k$ is the element in P satisfying (2.1).

Proof Put

$$
x_{1}=A x_{0}, \ldots, x_{n}=A x_{n-1}, \ldots, \quad n=1,2, \ldots
$$

Since $x_{0}$ and $A x_{0}$ are comparable and $A$ is $\varphi$-ordered contractive, $x_{1}=A x_{0}$ and $x_{2}=A x_{1}$ are comparable. By induction, it is not difficult to prove that for any natural number $n, x_{n}$ and $x_{n+1}$ are comparable. As $A$ is $\varphi$-ordered contractive, there exists $k \in P$ with $0 \leq r(k)<1$ such that for any natural number $n$,

$$
\begin{aligned}
\left(\varphi\left(x_{n+1}\right)-\varphi\left(x_{n}\right)\right) \vee\left(\varphi\left(x_{n}\right)-\varphi\left(x_{n+1}\right)\right) & =\left(\varphi\left(A x_{n}\right)-\varphi\left(A x_{n-1}\right)\right) \vee\left(\varphi\left(A x_{n-1}\right)-\varphi\left(A x_{n}\right)\right) \\
& \preceq k\left[\left(\varphi\left(x_{n}\right)-\varphi\left(x_{n-1}\right)\right) \vee\left(\varphi\left(x_{n-1}\right)-\varphi\left(x_{n}\right)\right)\right] \\
& \preceq \cdots \\
& \preceq k^{n}\left[\left(\varphi\left(A x_{0}\right)-\varphi\left(x_{0}\right)\right) \vee\left(\varphi\left(x_{0}\right)-\varphi\left(A x_{0}\right)\right)\right] .
\end{aligned}
$$

By the definition of ' $\preceq$ ' and the ordered contractive property of $A$, we get that

$$
\begin{aligned}
d\left(x_{n+1}, x_{n}\right) & \preceq\left(\varphi\left(x_{n+1}\right)-\varphi\left(x_{n}\right)\right) \vee\left(\varphi\left(x_{n}\right)-\varphi\left(x_{n+1}\right)\right) \\
& \preceq \cdots \\
& \preceq k^{n}\left[\left(\varphi\left(A x_{0}\right)-\varphi\left(x_{0}\right)\right) \vee\left(\varphi\left(x_{0}\right)-\varphi\left(A x_{0}\right)\right)\right] .
\end{aligned}
$$

For any pair of natural numbers $n, m$ with $m>n$, we have

$$
\begin{aligned}
d\left(x_{n}, x_{m}\right) & \leq d\left(x_{n}, x_{n+1}\right)+d\left(x_{n+1}, x_{n+2}\right)+\cdots+d\left(x_{m-1}, x_{m}\right) \\
& \leq\left(k^{n}+k^{n+1}+\cdots+k^{m-1}\right)\left[\left(\varphi\left(A x_{0}\right)-\varphi\left(x_{0}\right)\right) \vee\left(\varphi\left(x_{0}\right)-\varphi\left(A x_{0}\right)\right)\right] \\
& \leq\left(\sum_{i=0}^{\infty} k^{i}\right) k^{n}\left[\left(\varphi\left(A x_{0}\right)-\varphi\left(x_{0}\right)\right) \vee\left(\varphi\left(x_{0}\right)-\varphi\left(A x_{0}\right)\right)\right] \\
& =(e-k)^{-1} k^{n}\left[\left(\varphi\left(A x_{0}\right)-\varphi\left(x_{0}\right)\right) \vee\left(\varphi\left(x_{0}\right)-\varphi\left(A x_{0}\right)\right)\right] .
\end{aligned}
$$

Then by the same argument as that used in Theorem 3.1 of [26], we can prove that $\left\{x_{n}\right\}$ is a Cauchy sequence. Since $X$ is complete, there exists $x^{*} \in X$ such that $x_{n} \rightarrow x^{*}(n \rightarrow \infty)$. The continuity of $A$ implies that $x_{n+1}=A x_{n} \rightarrow A x^{*}(n \rightarrow \infty)$. So $A x^{*}=x^{*}$, that is, $x^{*}$ is a fixed point of $A$. Furthermore, by Lemma 2.1, we have

$$
\begin{aligned}
d\left(x^{*}, x_{0}\right) & =\lim _{n \rightarrow \infty} d\left(x_{n}, x_{0}\right) \\
& \preceq \lim _{n \rightarrow \infty} \sum_{i=1}^{n} d\left(x_{i}, x_{i-1}\right)
\end{aligned}
$$




$$
\begin{aligned}
& \leq \sum_{i=1}^{\infty} k^{i-1}\left[\left(\varphi\left(A x_{0}\right)-\varphi\left(x_{0}\right)\right) \vee\left(\varphi\left(x_{0}\right)-\varphi\left(A x_{0}\right)\right)\right] \\
& =(e-k)^{-1}\left[\left(\varphi\left(A x_{0}\right)-\varphi\left(x_{0}\right)\right) \vee\left(\varphi\left(x_{0}\right)-\varphi\left(A x_{0}\right)\right)\right] .
\end{aligned}
$$

Theorem 3.2 If $A: X \rightarrow X$ is $\varphi$-ordered contractive and there exists $x_{0} \in X$ such that for any natural number $n, x_{0}$ and $A^{n} x_{0}$ are comparable, then the same conclusions as those of Theorem 3.1 hold.

Proof Define $\left\{x_{n}\right\}$ by $x_{n}=A x_{n-1}(n=1,2, \ldots)$. By a proof similar to that of Theorem 3.1, one can prove easily that $\left\{x_{n}\right\}$ is a Cauchy sequence. The completeness of $X$ implies that there is $x^{*} \in X$ such that $x_{n} \rightarrow x^{*}(n \rightarrow \infty)$. Next, we show that $x^{*}$ is a fixed point of $A$.

For any pair of natural numbers $n, m$ with $n<m, x_{0}$ and $x_{m-n}=A^{m-n} x_{0}$ are comparable according to the given conditions. As $A$ is $\varphi$-ordered contractive, $A x_{0}$ and $A x_{m-n}$ are comparable. Continue this progress, we get that $x_{n}=A^{n} x_{0}$ and $x_{m}=A^{n} x_{m-n}=A^{m} x_{0}$ are comparable. Let $m \rightarrow \infty$, Lemma 2.2 shows that for any natural number $n, x_{n}$ and $x^{*}$ are comparable. Because $A$ is $\varphi$-ordered contractive, $A x_{n}$ and $A x^{*}$ are comparable and there exists $k \in P$ with $0 \leq r(k)<1$ such that

$$
\begin{aligned}
& \left(\varphi\left(A x_{n}\right)-\varphi\left(A x^{*}\right)\right) \vee\left(\varphi\left(A x^{*}\right)-\varphi\left(A x_{n}\right)\right) \\
& \quad \preceq k\left[\left(\varphi\left(x_{n}\right)-\varphi\left(x^{*}\right)\right) \vee\left(\varphi\left(x^{*}\right)-\varphi\left(x_{n}\right)\right)\right] .
\end{aligned}
$$

Noting the ordered contractive property of $A$, we have

$$
\begin{aligned}
d\left(x_{n+1}, A x^{*}\right) & =d\left(A x_{n}, A x^{*}\right) \preceq\left(\varphi\left(A x_{n}\right)-\varphi\left(A x^{*}\right)\right) \vee\left(\varphi\left(A x^{*}\right)-\varphi\left(A x_{n}\right)\right) \\
& \preceq k\left[\left(\varphi\left(x_{n}\right)-\varphi\left(x^{*}\right)\right) \vee\left(\varphi\left(x^{*}\right)-\varphi\left(x_{n}\right)\right)\right] .
\end{aligned}
$$

Let $u_{n}=d\left(x_{n+1}, A x^{*}\right), v_{n}=k\left[\left(\varphi\left(x_{n}\right)-\varphi\left(x^{*}\right)\right) \vee\left(\varphi\left(x^{*}\right)-\varphi\left(x_{n}\right)\right)\right], n=0,1,2, \ldots$ Then, for any natural number $n, u_{n} \leq v_{n}$. Notice that $u_{n}=d\left(x_{n+1}, A x^{*}\right) \rightarrow d\left(x^{*}, A x^{*}\right)$ and the continuity of $\varphi$, by Lemma 2.3, we have $d\left(x^{*}, A x^{*}\right) \preceq k\left[\varphi\left(x^{*}\right)-\varphi\left(x^{*}\right)\right]=\theta$, so $A x^{*}=x^{*}$.

Moreover, we get that

$$
\begin{aligned}
d\left(x_{n+1}, x_{n}\right) & \preceq\left(\varphi\left(x_{n+1}\right)-\varphi\left(x_{n}\right)\right) \vee\left(\varphi\left(x_{n}\right)-\varphi\left(x_{n+1}\right)\right) \\
& =\left(\varphi\left(A x_{n}\right)-\varphi\left(A x_{n-1}\right)\right) \vee\left(\varphi\left(A x_{n-1}\right)-\varphi\left(A x_{n}\right)\right) \\
& \preceq k\left[\left(\varphi\left(x_{n}\right)-\varphi\left(x_{n-1}\right)\right) \vee\left(\varphi\left(x_{n-1}\right)-\varphi\left(x_{n}\right)\right)\right] \\
& \preceq \cdots \\
& \preceq k^{n}\left[\left(\varphi\left(A x_{0}\right)-\varphi\left(x_{0}\right)\right) \vee\left(\varphi\left(x_{0}\right)-\varphi\left(A x_{0}\right)\right)\right] .
\end{aligned}
$$

Hence Lemma 2.1 gives that

$$
\begin{aligned}
d\left(x^{*}, x_{0}\right) & =\lim _{n \rightarrow \infty} d\left(x_{n}, x_{0}\right) \\
& \preceq \lim _{n \rightarrow \infty} \sum_{i=1}^{n} d\left(x_{i}, x_{i-1}\right)
\end{aligned}
$$




$$
\begin{aligned}
& \preceq \lim _{n \rightarrow \infty} \sum_{i=1}^{n} k^{i-1}\left[\left(\varphi\left(A x_{0}\right)-\varphi\left(x_{0}\right)\right) \vee\left(\varphi\left(x_{0}\right)-\varphi\left(A x_{0}\right)\right)\right] \\
& =(e-k)^{-1}\left[\left(\varphi\left(A x_{0}\right)-\varphi\left(x_{0}\right)\right) \vee\left(\varphi\left(x_{0}\right)-\varphi\left(A x_{0}\right)\right)\right] .
\end{aligned}
$$

Theorem 3.3 Let $A: X \rightarrow X$ be a continuous mapping satisfying the following conditions:

(i) There exist $\lambda_{1}, \lambda_{2} \in P$ with $0 \leq r\left(\lambda_{1}\right)+r\left(\lambda_{2}\right)<1$ such that for any comparable pair $x, y \in X, A x$ and Ay are comparable. Moreover, if $x$ and $A x, y$ and Ay are comparable, then

$$
\begin{aligned}
& (\varphi(A x)-\varphi(A y)) \vee(\varphi(A y)-\varphi(A x)) \\
& \preceq \lambda_{1}[(\varphi(A x)-\varphi(x)) \vee(\varphi(x)-\varphi(A x))] \\
& \quad+\lambda_{2}[(\varphi(A y)-\varphi(y)) \vee(\varphi(y)-\varphi(A y))] .
\end{aligned}
$$

(ii) There exists $x_{0} \in X$ such that $x_{0}$ and $A x_{0}$ are comparable.

Then $A$ has a fixed point $x^{*}$ in X. Furthermore, the iterative sequence $x_{n}=A x_{n-1}(n=$ $1,2, \ldots)$ converges to $x^{*}$ and

$$
d\left(x^{*}, x_{0}\right) \preceq\left[e-\left(e-\lambda_{2}\right)^{-1} \lambda_{1}\right]^{-1}\left[\left(\varphi\left(A x_{0}\right)-\varphi\left(x_{0}\right)\right) \vee\left(\varphi\left(x_{0}\right)-\varphi\left(A x_{0}\right)\right)\right]
$$

Proof Let $x_{n}=A x_{n-1}(n=1,2, \ldots)$. Since $x_{0}$ and $A x_{0}$ are comparable, according to the given condition (i) and by induction, it is easy to verify that for any natural number $n, x_{n}$ and $x_{n+1}=A x_{n}$ are comparable. Therefore

$$
\begin{aligned}
d\left(x_{n}, x_{n+1}\right) \preceq & \left(\varphi\left(x_{n}\right)-\varphi\left(x_{n+1}\right)\right) \vee\left(\varphi\left(x_{n+1}\right)-\varphi\left(x_{n}\right)\right) \\
= & \left(\varphi\left(A x_{n-1}\right)-\varphi\left(A x_{n}\right)\right) \vee\left(\varphi\left(A x_{n}\right)-\varphi\left(A x_{n-1}\right)\right) \\
\preceq & \lambda_{1}\left[\left(\varphi\left(A x_{n-1}\right)-\varphi\left(x_{n-1}\right)\right) \vee\left(\varphi\left(x_{n-1}\right)-\varphi\left(A x_{n-1}\right)\right)\right] \\
& +\lambda_{2}\left[\left(\varphi\left(A x_{n}\right)-\varphi\left(x_{n}\right)\right) \vee\left(\varphi\left(x_{n}\right)-\varphi\left(A x_{n}\right)\right)\right] \\
= & \lambda_{1}\left[\left(\varphi\left(x_{n}\right)-\varphi\left(x_{n-1}\right)\right) \vee\left(\varphi\left(x_{n-1}\right)-\varphi\left(x_{n}\right)\right)\right] \\
& +\lambda_{2}\left[\left(\varphi\left(x_{n+1}\right)-\varphi\left(x_{n}\right)\right) \vee\left(\varphi\left(x_{n}\right)-\varphi\left(x_{n+1}\right)\right)\right],
\end{aligned}
$$

which yields that

$$
\begin{aligned}
d\left(x_{n}, x_{n+1}\right) & \preceq\left(\varphi\left(x_{n}\right)-\varphi\left(x_{n+1}\right)\right) \vee\left(\varphi\left(x_{n+1}\right)-\varphi\left(x_{n}\right)\right) \\
& \preceq\left(e-\lambda_{2}\right)^{-1} \lambda_{1}\left[\left(\varphi\left(x_{n-1}\right)-\varphi\left(x_{n}\right)\right) \vee\left(\varphi\left(x_{n}\right)-\varphi\left(x_{n-1}\right)\right)\right] \\
& \preceq \cdots \\
& \preceq\left[\left(e-\lambda_{2}\right)^{-1} \lambda_{1}\right]^{n}\left[\left(\varphi\left(x_{0}\right)-\varphi\left(x_{1}\right)\right) \vee\left(\varphi\left(x_{1}\right)-\varphi\left(x_{0}\right)\right)\right] .
\end{aligned}
$$

Lemma 2.4 together with Lemma 2.5 shows that $r\left(\left(e-\lambda_{2}\right)^{-1} \lambda_{1}\right) \leq r\left(\left(e-\lambda_{2}\right)^{-1}\right) r\left(\lambda_{1}\right) \leq(1-$ $\left.r\left(\lambda_{2}\right)\right)^{-1} r\left(\lambda_{1}\right)$. As $r\left(\lambda_{1}\right)+r\left(\lambda_{2}\right)<1, r\left(\left(e-\lambda_{2}\right)^{-1} \lambda_{1}\right) \leq\left(1-r\left(\lambda_{2}\right)\right)^{-1} r\left(\lambda_{1}\right)<1$. Thus by the same proof as used in Theorem 3.1, we obtain that $\left\{x_{n}\right\}$ is a Cauchy sequence. As $X$ is complete, there exists $x^{*} \in X$ such that $x_{n} \rightarrow x^{*}(n \rightarrow \infty)$. The continuity of $A$ implies $x_{n+1}=A x_{n} \rightarrow$ 
$A x^{*}(n \rightarrow \infty)$. So $A x^{*}=x^{*}$. Furthermore, by Lemma 2.1 , we have

$$
\begin{aligned}
d\left(x^{*}, x_{0}\right) & =\lim _{n \rightarrow \infty} d\left(x_{n}, x_{0}\right) \\
& \preceq \lim _{n \rightarrow \infty} \sum_{i=1}^{n} d\left(x_{i}, x_{i-1}\right) \\
& \preceq \lim _{n \rightarrow \infty} \sum_{i=1}^{n}\left[\left(e-\lambda_{2}\right)^{-1} \lambda_{1}\right]^{i-1}\left[\left(\varphi\left(A x_{0}\right)-\varphi\left(x_{0}\right)\right) \vee\left(\varphi\left(x_{0}\right)-\varphi\left(A x_{0}\right)\right)\right] \\
& =\left[e-\left(e-\lambda_{2}\right)^{-1} \lambda_{1}\right]^{-1}\left[\left(\varphi\left(A x_{0}\right)-\varphi\left(x_{0}\right)\right) \vee\left(\varphi\left(x_{0}\right)-\varphi\left(A x_{0}\right)\right)\right] .
\end{aligned}
$$

Theorem 3.4 Suppose that $A: X \rightarrow X$ is a mapping satisfying the following conditions:

(i) There exist $\lambda_{1}, \lambda_{2} \in P$ with $0 \leq r\left(\lambda_{1}\right)+r\left(\lambda_{2}\right)<1$ such that for any comparable pair $x, y \in X, A x$ and Ay are comparable. Moreover, if $x$ and $A x, y$ and Ay are comparable, then

$$
\begin{aligned}
& (\varphi(A x)-\varphi(A y)) \vee(\varphi(A y)-\varphi(A x)) \\
& \preceq \lambda_{1}[(\varphi(A x)-\varphi(x)) \vee(\varphi(x)-\varphi(A x))] \\
& \quad+\lambda_{2}[(\varphi(A y)-\varphi(y)) \vee(\varphi(y)-\varphi(A y))] .
\end{aligned}
$$

(ii) There exists $x_{0} \in X$ such that for any natural number $n, x_{0}$ and $A^{n} x_{0}$ are comparable. Then the same conclusions as those in Theorem 3.3 hold.

Proof Set $x_{n}=A x_{n-1}(n=1,2, \ldots)$. It follows by the same method as in Theorem 3.3 that $\left\{x_{n}\right\}$ is a Cauchy sequence and there exists $x^{*}$ in $X$ such that $x_{n} \rightarrow x^{*}(n \rightarrow \infty)$. Next we show that $x^{*}$ is a fixed point of $A$.

Also, by a proof similar to that of Theorem 3.2 and by Lemma 2.2, we get that for any natural number $n, x_{n}$ and $x_{n+1}=A x_{n}$ are comparable, $x_{n}$ and $x^{*}$ are also comparable. According to the given condition (i), for any natural number $n, A x_{n}$ and $A x^{*}$ are comparable. Let $n \rightarrow \infty$, by Lemma 2.2, $x^{*}$ and $A x^{*}$ are comparable. So

$$
\begin{aligned}
& \left(\varphi\left(A x_{n}\right)-\varphi\left(A x^{*}\right)\right) \vee\left(\varphi\left(A x^{*}\right)-\varphi\left(A x_{n}\right)\right) \\
& \leq \lambda_{1}\left[\left(\varphi\left(A x_{n}\right)-\varphi\left(x_{n}\right)\right) \vee\left(\varphi\left(x_{n}\right)-\varphi\left(A x_{n}\right)\right)\right] \\
& \quad+\lambda_{2}\left[\left(\varphi\left(A x^{*}\right)-\varphi\left(x^{*}\right)\right) \vee\left(\varphi\left(x^{*}\right)-\varphi\left(A x^{*}\right)\right)\right] .
\end{aligned}
$$

Let $n \rightarrow \infty$, the continuity of $\varphi$ together with Lemma 2.3 implies that

$$
\begin{aligned}
\theta & \leq\left(\varphi\left(x^{*}\right)-\varphi\left(A x^{*}\right)\right) \vee\left(\varphi\left(A x^{*}\right)-\varphi\left(x^{*}\right)\right) \\
& \leq \lambda_{2}\left[\left(\varphi\left(A x^{*}\right)-\varphi\left(x^{*}\right)\right) \vee\left(\varphi\left(x^{*}\right)-\varphi\left(A x^{*}\right)\right)\right] .
\end{aligned}
$$

Note that $0 \leq r\left(\lambda_{2}\right)<1$, by Proposition 3.5(ii) of [26], we have

$$
\varphi\left(x^{*}\right)=\varphi\left(A x^{*}\right)
$$


The partial ordering in $X$ gives that

$$
d\left(x^{*}, A x^{*}\right) \preceq\left(\varphi\left(x^{*}\right)-\varphi\left(A x^{*}\right)\right) \vee\left(\varphi\left(A x^{*}\right)-\varphi\left(x^{*}\right)\right) .
$$

It is evident from (3.4) and (3.5) that $A x^{*}=x^{*}$, so $x^{*}$ is a fixed point of $A$.

By the same argument as in Theorem 3.3 and the partial ordering in $X$, we have

$$
\begin{aligned}
d\left(x_{n}, x_{n+1}\right) & \preceq\left(\varphi\left(x_{n}\right)-\varphi\left(x_{n+1}\right)\right) \vee\left(\varphi\left(x_{n+1}\right)-\varphi\left(x_{n}\right)\right) \\
& \preceq\left(e-\lambda_{2}\right)^{-1} \lambda_{1}\left[\left(\varphi\left(x_{n}\right)-\varphi\left(x_{n-1}\right)\right) \vee\left(\varphi\left(x_{n-1}\right)-\varphi\left(x_{n}\right)\right)\right] \\
& \preceq \cdots \\
& \preceq\left[\left(e-\lambda_{2}\right)^{-1} \lambda_{1}\right]^{n}\left[\left(\varphi\left(x_{1}\right)-\varphi\left(x_{0}\right)\right) \vee\left(\varphi\left(x_{0}\right)-\varphi\left(x_{1}\right)\right)\right] .
\end{aligned}
$$

From Lemma 2.1, we have

$$
\begin{aligned}
d\left(x^{*}, x_{0}\right) & =\lim _{n \rightarrow \infty} d\left(x_{n}, x_{0}\right) \\
& \preceq \lim _{n \rightarrow \infty} \sum_{i=1}^{n} d\left(x_{i}, x_{i-1}\right) \\
& \preceq \lim _{n \rightarrow \infty} \sum_{i=1}^{n}\left[\left(e-\lambda_{2}\right)^{-1} \lambda_{1}\right]^{i-1}\left[\left(\varphi\left(A x_{0}\right)-\varphi\left(x_{0}\right)\right) \vee\left(\varphi\left(x_{0}\right)-\varphi\left(A x_{0}\right)\right)\right] \\
& =\left[e-\left(e-\lambda_{2}\right)^{-1} \lambda_{1}\right]^{-1}\left[\left(\varphi\left(A x_{0}\right)-\varphi\left(x_{0}\right)\right) \vee\left(\varphi\left(x_{0}\right)-\varphi\left(A x_{0}\right)\right)\right] .
\end{aligned}
$$

Theorem 3.5 Assume that $A: X \rightarrow X$ is continuous and satisfies the following:

(i) There exist $\lambda_{1}, \lambda_{1} \in P$ with $0 \leq r\left(\lambda_{2}\right)<\frac{1}{2}$ such that for any comparable pair $x, y \in X$, Ax and Ay are comparable. Moreover, if $x$ and $A x, y$ and Ay are comparable, then

$$
\begin{aligned}
& (\varphi(A x)-\varphi(A y)) \vee(\varphi(A y)-\varphi(A x)) \\
& \leq \lambda_{1}[(\varphi(A x)-\varphi(y)) \vee(\varphi(y)-\varphi(A x))] \\
& \quad+\lambda_{2}[(\varphi(A y)-\varphi(x)) \vee(\varphi(x)-\varphi(A y))] .
\end{aligned}
$$

(ii) There exists $x_{0} \in X$ such that $x_{0}$ and $A x_{0}, x_{0}$ and $A^{2} x_{0}$ are comparable.

Then $A$ has a fixed point $x^{*}$ in X. Furthermore, the iterative sequence $x_{n}=A x_{n-1}(n=$ $1,2, \ldots)$ converges to $x^{*}$ and

$$
d\left(x^{*}, x_{0}\right) \preceq\left[e-\lambda_{2}\left(e-\lambda_{2}\right)^{-1}\right]^{-1}\left[\left(\varphi\left(A x_{0}\right)-\varphi\left(x_{0}\right)\right) \vee\left(\varphi\left(x_{0}\right)-\varphi\left(A x_{0}\right)\right)\right] .
$$

Proof Pick $x_{n}=A x_{n-1}(n=1,2, \ldots)$. Since $x_{0}$ and $A x_{0}, x_{0}$ and $A^{2} x_{0}$ are comparable, for any natural number $n, x_{n}$ and $x_{n+1}$ as well as $x_{n}$ and $x_{n+2}$ are comparable. Therefore $\varphi\left(x_{n}\right)$ and $\varphi\left(x_{n+1}\right), \varphi\left(x_{n}\right)$ and $\varphi\left(x_{n+2}\right)$ are comparable. It follows from Remark 2.1 that

$$
\begin{aligned}
\theta & \preceq\left(\varphi\left(x_{n}\right)-\varphi\left(x_{n+1}\right)\right) \vee\left(\varphi\left(x_{n+1}\right)-\varphi\left(x_{n}\right)\right) \\
& =\left(\varphi\left(A x_{n-1}\right)-\varphi\left(A x_{n}\right)\right) \vee\left(\varphi\left(A x_{n}\right)-\varphi\left(A x_{n-1}\right)\right) \\
& \preceq \lambda_{1}\left[\left(\varphi\left(A x_{n-1}\right)-\varphi\left(x_{n}\right)\right) \vee\left(\varphi\left(x_{n}\right)-\varphi\left(A x_{n-1}\right)\right)\right]
\end{aligned}
$$




$$
\begin{aligned}
& +\lambda_{2}\left[\left(\varphi\left(A x_{n}\right)-\varphi\left(x_{n-1}\right)\right) \vee\left(\varphi\left(x_{n-1}\right)-\varphi\left(A x_{n}\right)\right)\right] \\
= & \lambda_{2}\left[\left(\varphi\left(x_{n+1}\right)-\varphi\left(x_{n-1}\right)\right) \vee\left(\varphi\left(x_{n-1}\right)-\varphi\left(x_{n+1}\right)\right)\right] \\
\preceq & \lambda_{2}\left[\left(\varphi\left(x_{n+1}\right)-\varphi\left(x_{n}\right)\right) \vee\left(\varphi\left(x_{n}\right)-\varphi\left(x_{n+1}\right)\right)\right. \\
& \left.+\left(\varphi\left(x_{n}\right)-\varphi\left(x_{n-1}\right)\right) \vee\left(\varphi\left(x_{n-1}\right)-\varphi\left(x_{n}\right)\right)\right] .
\end{aligned}
$$

Therefore

$$
\begin{aligned}
\theta & \preceq\left(\varphi\left(x_{n}\right)-\varphi\left(x_{n+1}\right)\right) \vee\left(\varphi\left(x_{n+1}\right)-\varphi\left(x_{n}\right)\right) \\
& \preceq\left(e-\lambda_{2}\right)^{-1} \lambda_{2}\left[\left(\varphi\left(x_{n}\right)-\varphi\left(x_{n-1}\right)\right) \vee\left(\varphi\left(x_{n-1}\right)-\varphi\left(x_{n}\right)\right)\right] \\
& \preceq \cdots \\
& \preceq\left[\left(e-\lambda_{2}\right)^{-1} \lambda_{2}\right]^{n}\left[\left(\varphi\left(x_{1}\right)-\varphi\left(x_{0}\right)\right) \vee\left(\varphi\left(x_{0}\right)-\varphi\left(x_{1}\right)\right)\right] .
\end{aligned}
$$

The definition of the partial ordering in $X$ gives that

$$
\begin{aligned}
d\left(x_{n}, x_{n+1}\right) & \preceq\left(\varphi\left(x_{n}\right)-\varphi\left(x_{n+1}\right)\right) \vee\left(\varphi\left(x_{n+1}\right)-\varphi\left(x_{n}\right)\right) \\
& \preceq\left(e-\lambda_{2}\right)^{-1} \lambda_{2}\left[\left(\varphi\left(x_{n}\right)-\varphi\left(x_{n-1}\right)\right) \vee\left(\varphi\left(x_{n-1}\right)-\varphi\left(x_{n}\right)\right)\right] \\
& \preceq\left[\left(e-\lambda_{2}\right)^{-1} \lambda_{2}\right]^{n}\left[\left(\varphi\left(x_{1}\right)-\varphi\left(x_{0}\right)\right) \vee\left(\varphi\left(x_{0}\right)-\varphi\left(x_{1}\right)\right)\right] .
\end{aligned}
$$

Since $0 \leq r\left(\lambda_{2}\right)<\frac{1}{2},\left\{x_{n}\right\}$ is a Cauchy sequence. Hence there exists $x^{*} \in X$ such that $x_{n} \rightarrow x^{*}$ $(n \rightarrow \infty)$. The continuity of $A$ shows that

$$
A x^{*}=\lim _{n \rightarrow \infty} A x_{n}=\lim _{n \rightarrow \infty} x_{n+1}=x^{*},
$$

that is, $x^{*}$ is a fixed point of $A$. From Lemma 2.1, we have

$$
\begin{aligned}
d\left(x^{*}, x_{0}\right) & =\lim _{n \rightarrow \infty} d\left(x_{n}, x_{0}\right) \\
& \preceq \lim _{n \rightarrow \infty} \sum_{i=1}^{n} d\left(x_{i}, x_{i-1}\right) \\
& \preceq \lim _{n \rightarrow \infty} \sum_{i=1}^{n}\left[\left(e-\lambda_{2}\right)^{-1} \lambda_{2}\right]^{i-1}\left[\left(\varphi\left(A x_{0}\right)-\varphi\left(x_{0}\right)\right) \vee\left(\varphi\left(x_{0}\right)-\varphi\left(A x_{0}\right)\right)\right] \\
& =\left[e-\left(e-\lambda_{2}\right)^{-1} \lambda_{2}\right]^{-1}\left[\left(\varphi\left(A x_{0}\right)-\varphi\left(x_{0}\right)\right) \vee\left(\varphi\left(x_{0}\right)-\varphi\left(A x_{0}\right)\right)\right] .
\end{aligned}
$$

Theorem 3.6 Let $A: X \rightarrow X$ be a mapping and satisfy the following conditions:

(i) There exist $\lambda_{1}, \lambda_{2} \in P$ with $0 \leq r\left(\lambda_{2}\right)<1$ such that for any comparable pair $x, y \in X$, $A x$ and Ay are comparable. Moreover, if $x$ and $A x, y$ and Ay are also comparable, then

$$
\begin{aligned}
& (\varphi(A x)-\varphi(A y)) \vee(\varphi(A y)-\varphi(A x)) \\
& \leq \lambda_{1}[(\varphi(A x)-\varphi(y)) \vee(\varphi(y)-\varphi(A x))] \\
& \quad+\lambda_{2}[(\varphi(A y)-\varphi(x)) \vee(\varphi(x)-\varphi(A y))] .
\end{aligned}
$$


(ii) There exists $x_{0} \in X$ such that for any natural number $n, x_{0}$ and $A^{n} x_{0}$ are comparable. Then the same conclusions as those in Theorem 3.5 hold.

Proof Define $\left\{x_{n}\right\}$ by $x_{n}=A x_{n-1}(n=1,2, \ldots)$. As in the proof of Theorem 3.4 , there exists $x^{*} \in X$ such that $x_{n} \rightarrow x^{*}(n \rightarrow \infty)$ and

$$
\begin{aligned}
& \left(\varphi\left(A x_{n}\right)-\varphi\left(A x^{*}\right)\right) \vee\left(\varphi\left(A x^{*}\right)-\varphi\left(A x_{n}\right)\right) \\
& \preceq \lambda_{1}\left[\left(\varphi\left(A x_{n}\right)-\varphi\left(x^{*}\right)\right) \vee\left(\varphi\left(x^{*}\right)-\varphi\left(A x_{n}\right)\right)\right] \\
& \quad+\lambda_{2}\left[\left(\varphi\left(A x^{*}\right)-\varphi\left(x_{n}\right)\right) \vee\left(\varphi\left(x_{n}\right)-\varphi\left(A x^{*}\right)\right)\right] .
\end{aligned}
$$

Let $n \rightarrow \infty$, the continuity of $\varphi$ implies that

$$
\begin{aligned}
\theta & \preceq\left(\varphi\left(x^{*}\right)-\varphi\left(A x^{*}\right)\right) \vee\left(\varphi\left(A x^{*}\right)-\varphi\left(x^{*}\right)\right) \\
& \preceq \lambda_{2}\left[\left(\varphi\left(A x^{*}\right)-\varphi\left(x^{*}\right)\right) \vee\left(\varphi\left(x^{*}\right)-\varphi\left(A x^{*}\right)\right)\right] .
\end{aligned}
$$

Note that $0 \leq r\left(\lambda_{2}\right)<1$, by Proposition 3.5(ii) of [26], we have

$$
\varphi\left(x^{*}\right)=\varphi\left(A x^{*}\right)
$$

Since $x^{*}$ and $A x^{*}$ are comparable,

$$
d\left(x^{*}, A x^{*}\right) \preceq\left(\varphi\left(x^{*}\right)-\varphi\left(A x^{*}\right)\right) \vee\left(\varphi\left(A x^{*}\right)-\varphi\left(x^{*}\right)\right) .
$$

From (3.7) and (3.8), we have $A x^{*}=x^{*}$, so $x^{*}$ is a fixed point of $A$.

By the same method as in Theorem 3.3, we have

$$
\begin{aligned}
d\left(x_{n}, x_{n+1}\right) & \preceq\left(\varphi\left(x_{n}\right)-\varphi\left(x_{n+1}\right)\right) \vee\left(\varphi\left(x_{n+1}\right)-\varphi\left(x_{n}\right)\right) \\
& \preceq\left(e-\lambda_{2}\right)^{-1} \lambda_{2}\left[\left(\varphi\left(x_{n}\right)-\varphi\left(x_{n-1}\right)\right) \vee\left(\varphi\left(x_{n-1}\right)-\varphi\left(x_{n}\right)\right)\right] \\
& \preceq\left[\left(e-\lambda_{2}\right)^{-1} \lambda_{2}\right]^{n}\left[\left(\varphi\left(x_{1}\right)-\varphi\left(x_{0}\right)\right) \vee\left(\varphi\left(x_{0}\right)-\varphi\left(x_{1}\right)\right)\right] .
\end{aligned}
$$

Lemma 2.1 shows that

$$
\begin{aligned}
d\left(x^{*}, x_{0}\right) & =\lim _{n \rightarrow \infty} d\left(x_{n}, x_{0}\right) \\
& \preceq \lim _{n \rightarrow \infty} \sum_{i=1}^{n} d\left(x_{i}, x_{i-1}\right) \\
& \preceq \lim _{n \rightarrow \infty} \sum_{i=1}^{n}\left[\left(e-\lambda_{2}\right)^{-1} \lambda_{2}\right]^{i-1}\left[\left(\varphi\left(A x_{0}\right)-\varphi\left(x_{0}\right)\right) \vee\left(\varphi\left(x_{0}\right)-\varphi\left(A x_{0}\right)\right)\right] \\
& =\left[e-\left(e-\lambda_{2}\right)^{-1} \lambda_{2}\right]^{-1}\left[\left(\varphi\left(A x_{0}\right)-\varphi\left(x_{0}\right)\right) \vee\left(\varphi\left(x_{0}\right)-\varphi\left(A x_{0}\right)\right)\right] .
\end{aligned}
$$

Example 3.1 Let $\mathcal{A}=\mathbb{R}^{2}$. For each $x=\left(x_{1}, x_{2}\right) \in \mathcal{A}$, let $\|x\|=\left|x_{1}\right|+\left|x_{2}\right|$. The multiplication is defined by

$$
x y=\left(x_{1}, x_{2}\right)\left(y_{1}, y_{2}\right)=\left(x_{1} y_{1}, x_{2} y_{2}\right)
$$


Then $\mathcal{A}$ is a Banach algebra with unit $e=(1,1)$. Let $P=\left\{\left(x_{1}, x_{2}\right) \in \mathbb{R}^{2} \mid x_{1} \geq 0, x_{2} \geq 0\right\}$ and $X=\mathbb{R}^{2}$. A metric $d$ on $X$ is defined by

$$
d(x, y)=d\left(\left(x_{1}, x_{2}\right),\left(y_{1}, y_{2}\right)\right)=\left(\left|x_{1}-y_{1}\right|,\left|x_{2}-y_{2}\right|\right) \in P .
$$

Then $(X, d)$ is a complete cone metric space over the Banach algebra $\mathcal{A}$.

Now define mapping $T: X \rightarrow X$ by

$$
T(x, y)=\left(\ln \left(e^{x-2}+1\right), \tan \left(\frac{2}{\pi} \arctan (y+1)\right)\right) .
$$

Then $T$ has a fixed point in $X$.

In fact, let $k=\left(\frac{2}{e^{2}}, \frac{2}{\pi}\right) \in P$ and define $\varphi: X \rightarrow \mathcal{A}$ by $\varphi(x, y)=\left(-e^{x}-x,-\arctan (y+1)-y\right)$. Then $k \in P$ with $0<r(k)<1$ and it is not difficult to verify that $\varphi$ is continuous on $X$ and the partial ordering in $X$ can be induced by $\varphi$. Clearly, $T$ is continuous and for any comparable pair $x=\left(x_{1}, x_{2}\right), y=\left(y_{1}, y_{2}\right) \in X, T x$ and $T y$ are comparable. Moreover, by simple calculations, we can obtain that

$$
(\varphi(T x)-\varphi(T y)) \vee(\varphi(T y)-\varphi(T x)) \leq k[(\varphi(x)-\varphi(y)) \vee(\varphi(y)-\varphi(x))]
$$

Thus $T$ is $\varphi$-ordered contractive. Take $x_{0}=(-1,0)$, then $x_{0}=(-1,0) \leq T x_{0}=\left(\ln \left(e^{-3}+\right.\right.$ $\left.1), \tan \left(\frac{1}{2}\right)\right)$, that is, $x_{0}$ and $T x_{0}$ are comparable. Hence by Theorem 3.1, $T$ has a fixed point in $X$.

\section{Competing interests}

The authors declare that they have no competing interests.

\section{Authors' contributions}

All authors contributed equally to the writing of this paper. All authors read and approved the final manuscript.

Received: 5 January 2015 Accepted: 23 March 2015 Published online: 09 April 2015

\section{References}

1. Guo, D-J, Lakshmikantham, V: Coupled fixed point of nonlinear mappings with applications. Nonlinear Anal. 11, 623-632 (1987)

2. Guo, D-J, Lakshmikantham, V: Nonlinear Problems in Abstract Cone. Academic Press, New York (1988)

3. Sun, Y: A fixed point theorem for mixed monotone mappings with applications. J. Math. Anal. Appl. 156, 240-246 (1991)

4. Guo, D-J: Existence and uniqueness of positive fixed point for mixed monotone mappings and applications. Appl. Anal. 46, 91-100 (1992)

5. Rhoades, B-E: Some theorems on weakly contractive maps. Nonlinear Anal. 47, 2683-2693 (2001)

6. Caristi, J: Fixed point theorems for mappings satisfying inwardness conditions. Trans. Am. Math. Soc. 215, 241-251 (1976)

7. Huang, L-G, Zhang, X: Cone metric spaces and fixed point theorems of contractive mappings. J. Math. Anal. Appl. $332,1468-1476(2007)$

8. Rezapour, S, Hamlbarani, R: Some notes on the paper 'Cone metric spaces and fixed point theorems of contractive mappings'. J. Math. Anal. Appl. 345, 719-724 (2008)

9. Ilić, D, Rakočević, V: Quasi-contraction on a cone metric space. Appl. Math. Lett. 22(5), 728-731 (2009)

10. Radenović, S, Rhoades, B-E: Fixed point theorems for two non-self mappings in cone metric spaces. Comput. Math Appl. 57, 1701-1707 (2009)

11. Janković, S, Kadelburg, Z, Radenović, S: On the cone metric space: a survey. Nonlinear Anal. 74, $2591-2601$ (2011)

12. Gajić, L, Rakočević, V: Quasi-contractions on a nonnormal cone metric space. Funct. Anal. Appl. 46(1), 75-79 (2012)

13. Du, W-S: A note on cone metric fixed point theory and its equivalence. Nonlinear Anal. 72(5), 2259-2261 (2010)

14. Kadelburg, Z, Radenović, S, Rakočević, V: A note on the equivalence of some metric and cone metric fixed point results. Appl. Math. Lett. 24, 370-374 (2011)

15. Huang, H-P, Xu, S-Y, Liu, H, Radenović, S: Fixed point theorem and T stability of Picard iteration for generalized Lipschitz mappings in cone metric spaces over Banach algebra. J. Comput. Anal. Appl. (to appear)

16. Huang, H-P, Radenović, S: Some fixed point results of generalized Lipschitz mappings on cone $b$-metric spaces over Banach algebras. J. Comput. Anal. Appl. (to appear) 
17. Kadelburg, Z, Radenović, S, Rakócevíc, V: Topological vector space-valued cone metric spaces and fixed point theorems. Fixed Point Theory Appl. 2010, Article ID 170253 (2010)

18. Ding, H-S, Kadelburg, Z, Karapinar, E, Radenović, S: Common fixed points of weak contractions in cone metric spaces Abstr. Appl. Anal. 2012, Article ID 793862 (2012)

19. Rahimi, H, Radenović, S, Soleimani, G-R, Kumam, P: Quadrupled fixed point results in abstract metric spaces. Comput. Appl. Math. (2014). doi:10.1007/s40314-013-0088-5

20. Kadelburg, Z, Radenović, S: Generalized quasicontractions in orbitally complete abstract metric spaces. Fixed Point Theory 13(2), 527-536 (2012)

21. Ghafur, AB, Fadail, ZM, Abbas, M, Kadelburg, Z, Radenović, S: Some fixed points in abstract metric spaces. Abstr. Appl. Anal. 2012, Article ID 908423 (2012)

22. Radenović, S, Kadelburg, Z: Quasi-contractions on symmetric and cone symmetric spaces. Banach J. Math. Anal. 5(1), 38-50 (2011)

23. Kadelburg, Z, Radenović, S: A note on various types of cones and fixed point results in cone metric spaces. Asian J. Math. Appl. 2013, Article ID ama0104 (2013)

24. Liu, H, Xu, S-Y: Fixed point theorem of quasi-contractions on cone metric spaces with Banach algebras. Abstr. Appl. Anal. 2013, Article ID 187348 (2013)

25. Liu, H, Xu, S-Y: Cone metric spaces with Banach algebras and fixed point theorems of generalized Lipschitz mappings. Fixed Point Theory Appl. 2013, 320 (2013)

26. Xu, S-Y, Radenović, S: Fixed point theorems of generalized Lipschitz mappings on cone metric spaces over Banach algebras without assumption of normality. Fixed Point Theory Appl. 2014, 102 (2014)

\section{Submit your manuscript to a SpringerOpen ${ }^{\mathcal{O}}$ journal and benefit from:}

- Convenient online submission

- Rigorous peer review

- Immediate publication on acceptance

- Open access: articles freely available online

- High visibility within the field

- Retaining the copyright to your article 